\title{
NÓS, OS DO MAKULUSU E A PERSPECTIVA UTÓPICA DE JOSÉ LUANDINO VIEIRA
}

\author{
Leila de Almeida Barros \\ (Universidade Estadual de Londrina)
}

\section{RESUMO}

As definições da tradição enquanto continuidade, de um lado, e da modernidade enquanto ruptura, de outro, constituem-se hoje em verdadeiras ilusões de ótica social (BALANDIER, 1976). Do confronto permanente entre os fatores de manutenção de uma cultura e saber popular e as perturbações em cadeia trazidas pelo progresso surge, no seio das sociedades pós-coloniais, um terceiro tipo de sistema sociocultural, de caráter eminentemente instável. Como espaço determinante da constituição de identidades, esse novo mundo acaba por gerar indivíduos assinalados pelo signo da transitoriedade. Para o escritor angolano José Luandino Vieira, o sonho utópico de uma nação angolana livre das amarras do poder colonial surge justamente como resultado da soma entre o saber tradicional e o saber adquirido com a experiência da modernidade. Tomando como base as noções de tradição e modernidade presentes em As Dinâmicas Sociais, de Georges Balandier (1976), e em O discurso filosófico da modernidade, de Jürgen Habermas (2000), este trabalho busca compreender como se revela a perspectiva utópica de Luandino Vieira (1974) no romance Nós, Os do Makulusu. Para tanto, analisa-se a figura do narrador (Mais-Velho), que vaga pelas ruas de Luanda guiado pelo tempo da guerra e interceptado pelos filtros de sua memória. Nela, passado, presente e futuro se diluem para abarcar nessa tessitura narrativa, simultaneamente, a tradição e a modernidade.

PALAVRAS-CHAVE: tradição, modernidade, perspectiva utópica.

\section{ABSTRACT}

The definitions of tradition as an ongoing process, on the one hand, and modernity as rupture, on the other, are nowadays social optical illusions (BALANDIER, 1976). The continuous confrontation established between the maintaining factors of a popular culture and knowledge and the chained disruptions brought by progress generate a third type of sociocultu- 
ral system, eminently unstable, that emerges within post-colonial societies. As a space determinant of identity construction, this new world engenders wandering individuals. For the Angolan writer José Luandino Vieira, the utopian dream of an Angolan nation free from the shackles of the colonial power is precisely the result of a sum between the traditional knowledge and that knowledge which is gained from the experience of modernity. Based on the notions of tradition and modernity presented in As Dinâmicas Sociais, by Georges Balandier (1976), and O discurso filosófico da modernidade, by Jürgen Habermas (2000), this study aims at understanding how the utopian perspective of Luandino Vieira (1974) is revealed on the novel Nós, os do Makulusu. It analyzes the figure of the narrator (Mais-Velho), who wanders by the streets of Luanda led by the time of war and cut off by the filters of his memory. Here, past, present and future are diluted to encompass in this narrative structure, simultaneously, tradition and modernity.

KEYWORDS: tradition, modernity, utopian perspective.

\section{LUANDINO VIEIRA NO CONTEXTO DA LITERATURA AN- GOLANA}

Em A Formação do Romance Angolano, Rita Chaves (1999) evidencia que, fundada em bases étnicas histórica e culturalmente diferenciadas impelidas a unificar suas dissonantes vozes a fim de calar uma voz maior que todas elas - a do colonialismo português -, a nação angolana tem sua história assinalada pelo signo da crise e pela imagem da fratura. Por conseguinte, a consolidação de uma literatura nacional surge ao mesmo tempo como necessidade estética e como arma de combate para a afirmação da identidade de uma nação em processo de independência. A história da literatura angolana remonta ao final do século XIX e início do século XX, época em que suas primeiras manifestações literárias surgem sob a forma de extensa produção de poemas, folhetins e crônicas advinda da consolidação da imprensa no país. Mais adiante, na década de 1940, ouvem-se os primeiros burburinhos que mais tarde levariam às discussões de projetos para a libertação das colônias portuguesas na Casa dos Estudantes do Império (CEI), espaço de discussão entre estudantes africanos radicados em Portugal que mantinham, então, diálogo direto com as mais variadas propostas e correntes artísticas, como o movimento da Negritude e as correntes neorrealistas da literatura e do cinema.

O movimento dos "Novos Intelectuais de Angola” - projeto artístico que tem como norte a invenção e a resistência - marca de forma definitiva o início de um embate com o poder colonial por meio da valorização e do apreço pela cultura nacional. Munida com uma intencionalidade artística de caráter didático que busca concretizar o sonho da independência através da estabilização de uma consciência nacional, a produção poética angolana assume, nesse período, de acordo com Inocência Mata (2001), uma "coletivização da voz" capaz de despertar nos indivíduos a necessida- 
de - concretizada em seu mote: "Vamos descobrir Angola!" - de redescobrir as origens, tradições e mitos angolanos.

$\mathrm{Na}$ década seguinte, sem que perdesse força ou importância no contexto de luta pela libertação, essa produção poética dá lugar a uma prosa "revigorada no contato com a sociedade em visível processo de transformação" (CHAVES, 1999, p. 47), o que suscita um redelineamento no mapa literário de Angola. De acordo com Chaves (1999), Luandino Vieira está entre os principais representantes dessa nova fase. Para ela, a consolidação do romance angolano dar-se-ia de fato pelas mãos desse escritor, que obtém sucesso ao "conjugar a militância ostensiva, exigida pelo momento, com a ousadia de um projeto literário fundado em tão agudas crises" (CHAVES, 1999, p. 161). A valorização dos elementos tradicionais e o uso de elementos de uma nacionalidade incipiente dão forma à perspectiva utópica de Luandino de uma nação angolana livre do poder colonial, que seria a junção exata entre o tradicional e o moderno. Tal perspectiva parece perpassar toda a sua produção literária e pode ser constatada desde suas primeiras publicações. Entretanto, para Vima Lia Martin (2005, p. 80), é apenas com a publicação de Luuanda, em 1974, que:

a complexidade das relações sociais, culturais e políticas típicas dos espaços marginais luandenses assume maior destaque, condicionando a escrita literária - que se torna intensamente oralizada - e rompendo com um registro mais simplificado da realidade.

A cidade de Luanda, espaço em que se desenrola esta e a maior parte de suas narrativas, é também escolhida por Luandino como cenário para Nós, os do Makulusu (1974), obra que aqui se impõe como objeto de estudo. Segundo Chaves (1999, p. 173), a capital angolana seria justamente o local em que as marcas da modernidade e do contato com a cultura e a tradição europeia seriam mais visíveis e recorrentes e por isso "a pluralidade manifesta na coexistência de línguas, tradições e códigos culturais variados transformam a cidade numa metáfora viva do país".

\section{NÓS, OS DO MAKULUSU: ALGUMAS CONSIDERAÇÕES}

Nós, os do Makulusu retrata uma Angola em plena luta pela independência. Suas personagens, diferentes na cor e contraditórias em suas posições ideológicas, encontram-se dispersas no momento presente, ainda que no passado estivessem unidas por uma forte amizade. Os irmãos Mais-Velho e Maninho, de cor branca, são filhos de colonos portugueses; Paizinho, o meio-irmão mestiço, é filho do pai de Mais-Velho e Maninho com uma angolana; e Kibiaka, de cor negra e filho legítimo da terra, é o amigo fiel dos três irmãos. Passado o tempo despreocupado da infância e instaurando-se a tensão das lutas pró-independência, Maninho acaba se filiando ao exército colonial português, enquanto Paizinho e Kibiaka decidem atuar em favor do povo angolano, o primeiro na militância clandestina e 
o segundo na guerrilha. Assim, os quatro acabam por se afastar cada vez mais de um tempo de harmonia que se encontra para sempre perdido e que havia se concretizado em um pacto de amizade na caverna do Makokaloji.

Selado tanto em português quanto em quimbundo - o que sinaliza o desejo de eliminar de vez as diferenças que insistiam em separá-los -, o pacto poderia ser lido, segundo Julio Cesar Machado de Paula (2010), como metáfora de uma tentativa de retornar ao útero da terra africana para de lá renascer sem a marca da segregação imposta pelo colonialismo europeu:

Vento por cima das cabeças, pemba nas mãos, amassada no sangue, olhos brancos de flores de mupinheira, vermelhos olhos de bagas de cassuneira a olharem nossos pulsos todos colados uns nos outros e as vozes vêm eu oiço olho o espelho dos quatro olhos que me olham e me olharam lá também:

- Juro sangue-cristo, hóstia consagrada, cocô de cabrito, não trair nada!

Paizinho, sacerdote mulato:

- Nossa amizade, traição nada!

Kibiaka procurador de maquixes e quinzares, tradutor:

- Ukamba uakamba... (VIEIRA, 1991, p. 40).

A separação dos amigos na vida adulta, em razão de ideais políticos divergentes, concretiza-se através da morte de Maninho, da prisão de Paizinho e da fuga de Kibiaka, restando apenas Mais-Velho para "contar a história" dos indivíduos que um dia se denominaram "Nós, os do Makulusu". Poder-se-ia dizer, portanto, que a narrativa tece, com uma mesma linha, o reviver de Mais-Velho de uma infância impetuosa pelas ruas do Makulusu e seu presente de gosto amargo, guiado pela morte de Maninho e de tantos outros que perderam suas vidas em nome de uma guerra sem porquês.

A questão da morte, tão central a essa narrativa, assume aqui duas formas: a física, que se materializa na figura de Maninho, e a psicológica, representada, sobretudo, por Mais-Velho, mas também pelas figuras de Kibiaka e Paizinho. A morte física diz respeito ao sentido mais literal do substantivo, que em Angola decorre principalmente das guerras pró-libertação ou das investidas contrarrevolucionárias do poder colonial. Outro sentido, mais amplo e de maior importância, é o metafórico, aquele referente à morte individual e social: do angolano e de Angola. Decorrente do calar das vozes de toda a nação, os indivíduos que sofrem uma morte em termos psicológicos estão perdidos, à deriva - psicológica, social e espacialmente. Sim, espacialmente, pois o filho de uma nação marcada pelo jugo do colonialismo nasce também sem pátria, porque sem história para chamar de sua.

A crise que se instaura com a consolidação do sistema colonial em Angola tem reflexos no fazer literário de seus escritores, sobretudo no que diz respeito à construção linguística de seus textos. Nesse sentido, a 
escolha de Luandino em Nós, os do Makulusu parece ser a de inventar uma linguagem "capaz de quebrar o silêncio ditado pela colonização" (CHAVES, 1999 , p. 176). Para tanto, utiliza-se de termos e estruturas do quimbundo, bem como de expressões em latim e neologismos no intuito de "adaptar a língua do dominador à expressão da visão de mundo do dominado" (CHAVES, 1999, p. 179). Poder-se-ia inclusive dizer que a brincadeira que faz com metáforas, neologismos e com a fala quotidiana e sintaxe popular seria uma tentativa do escritor de encontrar uma autêntica angolanidade em sua escrita. Para Paula (2010, p. 124), está-se ainda diante de um texto que brinca com "a justaposição de orações, sobrepondo-se às associações estabelecidas por nexos lógico-causais", que "permite a passagem de uma ideia a outra ou de um tempo a outro de forma imediata, ou seja, pela livre associação". É o caso do episódio em que o cheiro do mar, no tempo presente, lembra Mais-Velho do dia em que ele, Maninho e Rute navegavam. Imediatamente, o passado vem invadir a tessitura narrativa:

Desembeco na Travessia da Sé e é o cheiro a mar que me rusga. Mas quero sentir-lhe todo, não posso, não aceita, não lhe deixa o ramo branco das flores que estou a levar, o fato escuro que pedi emprestado e a gravata disfarça. Não pode: mar mesmo só cheira a mar num corpo nu.

- Xalados, vocês!...

O barco solto camba e não aproa e os loiros cabelos de Maninho nas minhas mãos no meio dos meus dedos e o pé dele no meu peito: dentro de água, ridos e felizes - e Rute séria e zangada, sem medo mas me avisando:

- Tu, Mais-Velho! Vem tomar conta do leme! Nado mal, sabes? E vocês comeram que nem uns burros e aí dentro de água... (VIEIRA, 1991, p. 24-25)

Tecidas algumas considerações sobre a sua linguagem e narrativa não-lineares, vale ainda ressaltar a maneira peculiar com que é distinguida a cronologia nesse texto. Longe de o ser por meio da menção a dias e anos de um calendário comum, em Nós, os do Makulusu conta-se o tempo pelos anos da guerra: "Me arrepio todo, faltam vinte minutos para o ano III da guerra" (VIEIRA, 1991, p. 120). Dessa forma, cria-se um tempo novo, alternativo, que não mais se acerta "pelas horas da Europa" e que trabalha "oleado com suor e sangue" guiado pelos conflitos traumáticos que se repetem a cada dia, tendo a morte como "uma instituição nacional e familiar, quotidiana" (VIEIRA, 1991, p. 99).

Makulusu, nome de um antigo musseque de Luanda que fora mais tarde transformado em bairro, tem sua tradução em português na palavra “cruzes". Para Paula (2010, p. 125), o caminho percorrido pelo cortejo de Maninho "é, literalmente, uma 'Via Crúcis', um caminho das cruzes". Contudo, poder-se-ia ainda pensar na escolha do nome do antigo musseque, espaço em que habitam as memórias infantis de Mais-Velho, como forma 
de remeter ao sentido de outra palavra que deriva de cruzes: o cruzamento. De fato, diante das contradições dos novos tempos, é como se os amigos se decidissem por seguir, separadamente, um dos quatro caminhos que se abrem a partir de um cruzamento - em si, metáfora para o passado, isto é, para o ponto em comum que mantinha o grupo unido.

A frase final do romance, "Nós, os do Makulusu?" (VIEIRA, 1991, p. 121), além de realçar seu caráter inconclusivo - pois mesmo quando cessa o discurso ainda se fazem ouvir os ecos das interrogações de um narrador-personagem deslocado de si mesmo -, também parece colocar em questão o próprio pronome nós, já que o tempo presente em que vivem os quatro amigos se caracteriza pela individualidade e pela desunião.

Para Chaves (1999), não é de se espantar que o autor tenha feito a escolha por um narrador que, sempre desconfiado, interroga a si e aos demais, pois a forma pulverizada de recontar os acontecimentos de sua vida é, em si, manifestação de uma insatisfação no que diz respeito aos procedimentos convencionais da narrativa:

O ritmo contínuo da prosa tradicional não poderia dar conta do mundo em rodopios que coube à personagem narradora viver. Para tal, ele recorre às repetições, às elipses, às metáforas, antíteses e paradoxos, à musicalidade, aos desvios da norma gramatical, tudo caminhando para fazer da antidiscursividade a expressão dessa maneira de estar no mundo (CHAVES, 1999, p. 178).

Vai-se de certa forma de encontro ao que diz Walter Benjamin (1985), para quem o surgimento do romance moderno e a consolidação da burguesia e da imprensa seriam os primeiros indícios da morte da narrativa, já que o romance, tendo o indivíduo isolado como base, não procede nem se alimenta da tradição oral e a preocupação com a plausibilidade das informações característica da imprensa leva o mítico ou o miraculoso a serem rejeitados em detrimento de um saber científico. Nesse sentido, a arte de narrar estaria em vias de extinção porque, sendo extinta a dimensão utilitária da narrativa, que se dá graças à sabedoria do narrador, aquele "que sabe dar conselhos" (BENJAMIN, 1985, p. 200), perde-se sua natureza verdadeira. Para o peregrino narrador de Nós, os do Makulusu, não há verdade ou certeza absoluta, sendo qualquer indício de sabedoria relativizado:

Eu sei, mas para ter a certeza, que não posso nunca ter, não é uma coisa feita por medida, como um fato, não tem uma certeza na medida de cada qual mesmo que cada qual vista a sua certezinha consigo e sem ela não se pode viver, preciso de te ouvir dizer o que eu sei bem, mas que, dito por ti, por outro alheio, é mais certo: o teu relativo vira absoluto meu - solidariedade, é assim? - e vai também me tranquilizar, nascer a certeza que depois vou destruir e destruindo-lhe para lhe reconstruir e ir assim, contigo que não és só tu 
mas nós, os do Makulusu, fabricando, não a certeza, mas certezas que vão nos ajudar a ser nem cobardes nem heróis: homens só. Dos cobardes não reza a história, mas o pior, Maninho, quantos mais heróis tem um povo, mais infeliz é.

Preciso acabar com os heróis? (VIEIRA, 1991, p. 114).

Theodor Adorno (2003), em seu ensaio "Posição do narrador no romance contemporâneo", acredita que o lugar ocupado por esse novo tipo de narrador é paradoxal, pois o realismo, imanente ao romance desde sua origem, torna-se questionável desde o século XIX até os dias de hoje. É quando entra em cena um narrador que, numa atitude contra "a mentira da representação" (ADORNO, 2003, p. 60), enseja retirar da narrativa seu caráter de palco italiano, que leva o leitor a compactuar com a ilusão da representação literária. Com o advento da modernidade, a identidade da experiência é desintegrada, assim como o senso de comunidade que antes unia os indivíduos em uma vida coletiva, e o mundo em que vive esse novo narrador passa a ser aquele em que "a atitude contemplativa tornou-se um sarcasmo sangrento, porque a permanente ameaça da catástrofe não permite mais a observação imparcial, e nem mesmo a imitação estética dessa situação." (ADORNO, 2003, p. 61)

Reconhece-se, além disso, uma impotência diante da supremacia do mundo das coisas, aquele em que "quanto mais firme o apego ao realismo da exterioridade, ao gesto do 'foi assim', tanto mais cada palavra se torna um mero 'como se"' (ADORNO, 2003, p. 58). É por isso que, confinado a essa nova contradição, o narrador acaba por fabricar não uma, mas várias certezas, como diz a voz narrativa de Nós, os do Makulusu. Acerca do desencantamento do narrador com as fissuras e contradições deste novo mundo, o que acaba se refletindo esteticamente, o crítico brasileiro Silviano Santiago, em seu ensaio "O narrador pós-moderno", afirma que:

Há um ar de superioridade ferida, de narcisismo esquartejado no narrador pós-moderno, impávido por ser ainda portador de palavra num mundo onde ela pouco conta, anacrônico por saber que o que a sua palavra pode narrar como percurso de vida pouca utilidade tem. (SANTIAGO, 2002, p. 56)

Grande parte das narrativas contemporâneas, prossegue Santiago (2002), vai transformar tanto a figura do narrador como a do leitor, ambas impotentes diante da palavra agora destituída de autoridade, em meros espectadores de uma experiência alheia, por isso a importância que recai sobre a personagem na ficção dos dias de hoje. Nesse sentido, a palavra escrita só alcança durar numa sociedade pós-industrial porque esse narrador - que é "a contradição e a redenção da palavra na época da imagem" (SANTIAGO, 2002, p. 60) - precisa dar fala ao outro para poder encontrar uma fala para si. É por isso que Mais-Velho diz: "preciso de te ouvir dizer o que eu sei bem, mas que, dito por ti, por outro alheio, é mais certo: o teu relativo vira absoluto meu" (VIEIRA, 1991, p. 114). 
Também para Adorno (2003, p. 61), essa nova distância que se estabelece entre narrador e leitor é uma das consequências estéticas de sua decepção com a nova conjuntura e do reconhecimento de um novo estatuto da palavra. Por isso, à fixidez característica do romance tradicional dá-se lugar a uma perspectiva em que o leitor é conduzido pela narrativa como que através de uma câmera de cinema, em que ele é "ora deixado do lado de fora, ora guiado pelo comentário até o palco, os bastidores e a casa de máquinas" (ADORNO, 2003, p. 61).

É o que ocorre em Nós, os do Makulusu, em que o leitor percorre ao lado de Mais-Velho as ruas de Luanda - essas "ruas escondidas ao progresso... ruas de utopias... ruas personalizadas, coloniais, colonialistas, ruas de sangue..." (VIEIRA, 1991, p. 13) - e, nessa travessia, tem acesso às suas avenidas e ruas principais e aos seus becos mais recônditos, através de um ponto de vista que permite visões ora panorâmicas, ora microscópicas das cissuras do processo de colonização. Dessa forma, o narrador - partindo do litoral para o interior da cidade e refazendo em sua peregrinação os passos do colonizador - passa por locais que servirão de pano de fundo para o reviver e o aflorar de suas memórias: a rua dos Mercadores, a Igreja de Nossa Senhora do Carmo de Ingombota, o cemitério do Alto das Cruzes e as próprias ruas do musseque de Makulusu. É, portanto, de acordo com os filtros de sua memória que Mais-Velho organiza o tempo da narrativa com base nas contradições de sua conjuntura social. Dessa forma, ignora-se uma linearidade narrativa que "se revela incompatível com a consciência aguda de uma realidade estilhaçada" (CHAVES, 1999, p. 175), de que fazem parte esses indivíduos, sendo o cortejo para o enterro de Maninho o único fio condutor capaz de situar o leitor no tempo presente. Perpassando as perspectivas de todas as personagens, o monólogo desse narrador-personagem é em verdade um fluxo de consciência inexato em que se misturam ao hoje o ontem e o amanhã.

Tudo isso exposto, enfatiza-se que a figura de Mais-Velho incita a discussão de duas importantes questões. A primeira diz respeito à problemática da identidade do sujeito pós-colonial, conforme suscitada por Chaves (1999). Mas, para além dela, entra em cena a discussão sobre o novo lugar do narrador contemporâneo, conforme discutido por Adorno (2003), Benjamin (1993) e Santiago (2002). Não cabe aqui buscar por respostas, pois, como Mais-Velho, acredita-se não ser possível fabricar a certeza, mas várias certezas - que são, em verdade, apenas suposições.

Tão lacunar quanto o contexto social de que faz parte, na tentativa de narrar o outro para narrar a si mesmo, Mais-Velho observa seu ambiente de forma distanciada, ao mesmo tempo em que nele se integra e se perde. Tendo como norte o relógio da guerra, de um lado, e os filtros da memória, de outro, no centro da narrativa de Nós, os do Makulusu, unidos em uma mesma figura, estão personagem e narrador: à deriva e em fluxo. Nas entrelinhas, a indicação do imperativo de pensá-los em novos moldes - sem que seja preciso, contudo, fixa-los nessa ou naquela categoria, já que 
o que mudou, e essa parece ser uma premissa geral da literatura contemporânea, não foram os problemas (de ordem narrativa ou não), mas a forma de encará-los: "As ações do homem não são diferentes em si de uma geração para outra, muda-se o modo de encará-las, de olhá-las. O que está em jogo não é o surgimento de um novo tipo de ação, inteiramente original, mas a maneira diferente de encarar." (SANTIAGO, 2002, p. 54)

\section{A PERSPECTIVA UTÓPICA DE LUANDINO VIEIRA}

Como último objeto desta análise, faz-se importante compreender como se revela em Nós, os do Makulusu a perspectiva utópica de Luandino de uma nação angolana livre do poder colonial - que é, em verdade, uma soma entre o saber tradicional e o saber adquirido com a experiência da modernidade. De acordo com Chaves (1999), nas obras de Luandino, essa junção se faria mais clara literariamente na utilização de elementos típicos da modernidade, como a experimentação contínua da linguagem e da estrutura narrativa, em conjunção com a invocação de elementos da tradição angolana, resgatando-se um universo popular capaz de energizar a carga lírica do texto. Dessa forma, o autor revisita as raízes angolanas de olho no porvir, pois, "[d]espido do saudosismo imobilista, seu trabalho prefere, na verdade, envolver num só abraço a tradição e a modernidade como forças conjugadas para viabilizar a coerência e o alcance do verbo" (CHAVES, 1999, p. 184).

Com relação às categorias de tradição e modernidade, de acordo com o sociólogo francês Georges Balandier em seu livro As Dinâmicas Sociais, é nas sociedades em processo de expansão, como é o caso da angolana, que se faz melhor entrever "o afrontamento do tradicional e do moderno" tornando-se, nesse caso, "compreendido da maneira mais aparente, com um verdadeiro efeito de ampliação" (BALANDIER, 1976, p. 98).

Todo o pensamento social do século XVIII motivou uma visão dualista, largamente compartilhada, que opõe tradição versus modernidade - desde as concepções filosóficas de Auguste Comte e Max Weber, que atribuem às sociedades ocidentais modernas ares de eficiência e progresso em relação às sociedades ditas tradicionais, até a interpretação marxista das etapas que determinariam a sucessão das formas sociais e a teoria evolucionista que atravessa o horizonte de pesquisa dos primeiros antropólogos. Às já corriqueiras adjetivações, em que a primeira seria vista como "integralmente autóctone", enquanto a segunda como diametralmente estrangeira, junta-se o reforço da ideia de que "tudo aquilo que não corresponde ao modelo da sociedade industrial avançada - vista como criadora constantemente ativa da modernidade - é tido como tradicional" (BALANDIER, 1976, p. 100). Contudo, uma análise mais ponderada da realidade dessas duas conjunturas quando em convivência permitiria "compreender a dialética que age entre um sistema tradicional (degradado) e um sistema novo (determinado do exterior)", e que faz emergir de seu núcleo um terceiro 
sistema, de caráter “instável, mas portador da modernidade autêntica" (BALANDIER, 1976, p. 99, grifo do autor).

A dialética que se opera entre o tradicional e o moderno não só faz romper o poder sacralizado tradicional, como também traz em cena uma terceira conjuntura que se originaria a partir desse confronto. Isto posto, fica evidente que, de um ponto de vista social, é ilusório definir a tradição enquanto continuidade, de um lado, e a modernidade enquanto ruptura, de outro. Nesse sentido:

Uma interpretação dinâmica continua sendo indispensável [...] Ajuda a reconhecer melhor o caráter heterogêneo de toda sociedade que revela, sempre, elementos de "idade diferente" - sequelas de sua história - coexistentes de maneira mais ou menos contraditória, mais ou menos eficiente (BALANDIER, 1976, p. 221, grifo do autor).

Jürgen Habermas, em $O$ discurso filosófico da modernidade, dá início a seu livro contrapondo duas concepções de tempo e, consequentemente, duas formas de lidar com a questão da modernidade: o Zeitgeist (espírito do tempo), de Hegel, contrapõe-se à ideia de Jetztzeit (tempo-presente), de Walter Benjamin. Para Hegel, os novos e modernos tempos, quando contrapostos à época medieval, significam um total rompimento e o início do processo de transformação do passado. Nesse sentido, o espírito do tempo põe em cena novas experiências advindas do progresso e acelera os acontecimentos históricos em busca do futuro. A modernidade, essa época orientada exclusivamente para o porvir, "não pode e não quer tomar dos modelos de outra época os seus critérios de orientação, ela tem de extrair de si mesma a sua normatividade" (HABERMAS, 2000, p. 12). Essa premissa, que Hegel tomará como o próprio objetivo de sua filosofia - pois a filosofia só pode obter o conceito que forma de si mesma a partir da formação de um conceito filosófico da modernidade -, se desdobrará em inúmeras dificuldades para o idealista alemão. De fato, a modernidade não consegue se autocertificar com base em si mesma, pois o próprio Hegel acaba por concluir que o mundo moderno tende à crise: ele é, ao mesmo tempo, um mundo do progresso e aquele do espírito alienado. Ora, se a modernidade, para conceituar-se, tem de encontrar bases nas próprias cisões que produz, não é de surpreender que sua primeira tentativa de conceituação na esteira das ideias do Zeitgeist não apenas tenha fracassado como também acabou se tornando "originalmente uma crítica da modernidade” (HABERMAS, 2000, p. 25).

Para Habermas (2000), não se incorre em tais impasses quando se opta pela concepção benjaminiana de Jetztzeit. De acordo com Jeanne-Marie Gagnebin, a fim de compreender a visão de tempo-presente benjaminiana e o tipo de relação que se estabelece quando ela se volta para o passado, é preciso distinguir entre uma relação de apropriação e de uma atividade historicamente responsável. Na primeira, os valores do passado tidos 
como eternos ou atemporais são apropriados pelo presente por interesses próprios para que "não raro figuras e valores muito vagos e amplos [sejam] encontrados e exibidos como 'ainda e sempre atuais' apesar de sua roupagem caduca” (GAGNEBIN, 2013, p. 183). Essa concepção de atualidade/ temporalidade é em si rasa, nos dizeres da autora, pois, vistas sob o prisma do eterno, as obras do passado são eleitas como canônicas por uma classe dominante ao mesmo tempo em que são por ela declaradas como mortas. A essa apropriação acrítica do passado, essa "operação 'tapa-buraco"' (GAGNEBIN, 2013, p. 184), opõe-se aquela que promoverá uma redenção do passado em uma atividade historicamente responsável, fazendo do ontem não mais um espaço que antecede o hoje em uma linha cronológica do tempo, mas, "ao contrário, momentos esquecidos do passado e momentos imprevisíveis do presente, justamente porque são separados, portanto distantes, interpelam-se mutualmente numa imagem mnêmica que cria uma nova intensidade temporal" (GAGNEBIN, 2013, p. 186, grifo da autora).

A possibilidade de compreensão de um novo sentido - ou dos múltiplos sentidos - do passado determinaria, assim, outra concepção de atualidade, colocando em cheque uma narrativa dominante da História, aquela que perpetua a dicotomia vencedores-vencidos com base em uma única versão dos fatos. Fatos estes que são tidos, conforme a perspectiva de tempo hegeliana, como acabados, do qual não se poderia mais retirar nenhuma seiva, nem neles vislumbrar qualquer vestígio da tensão de uma luta que ecoa tanto no presente quanto no futuro, como é o caso da luta contra o poder colonial em África. É essa concepção de modernidade, tida como um processo evolutivo que precisa romper e renovar continuamente uma época anterior a ela, que perpetua, ao longo dos séculos, os preconceitos que interferem na percepção real do continente africano, tido como primitivo e pré-histórico antes da invasão do homem europeu. Assim, conforme apontado por Balandier (1976), aquilo que não corresponde ao padrão da sociedade industrial avançada é relegado, em África, à esfera do tradicional, declarado, nos termos de Gagnebin (2013, p. 184), como "espólio de um morto", um âmbito social já "embalsamado e engavetado".

Dito isso, o que parece faltar à Hegel é a compreensão de que a modernidade - e, mais amplamente, a História - não pode se dar como algo inovador se ela não se propuser a resolver as próprias contradições de seu passado. É justamente isso que Benjamin (2006) pretende com seu Jetztzeit, um tempo presente que deve estar sempre de olho no destino das gerações futuras e na redenção das gerações passadas, já que "a expectativa do novo no futuro só se cumpre por meio da reminiscência de um passado oprimido" (HABERMAS, 2000, p. 19, grifo do autor). Ao promover uma apropriação das experiências do passado nessa perspectiva de solidariedade histórica universal, o tempo de hoje torna-se o local de onde prossegue um acontecer contínuo da tradição. Não só isso, quando a modernidade se engaja em uma atividade historicamente responsável para com o passado, encontra-se principalmente com aquilo que não fora satisfeito naquele 
tempo e que, portanto, caso não seja redimido, causará mais lacunas no futuro. Dessa forma, os desejos do futuro, começo e fim do Zeitgeist hegeliano, só se materializariam a partir da consciência de que se depende do que já foi para a construção do que virá.

Ora, crê-se que nas entrelinhas de Nós, os do Makulusu deixa-se entrever um importante ensinamento: se Maninho, Mais-Velho, Paizinho e Kibiaka estão dispersos no momento presente - e, tudo indica, estarão mais ainda no futuro -, é porque, não conseguindo mais divisar o passado harmônico que os unia e que fora aniquilado com a chegada do colonizador e da modernidade, movem-se atordoados pelo tempo da guerra e no terreno da morte: "E enquanto não podemos nos entender porque só um lado de nós cresceu, temos de nos matar uns aos outros" (VIEIRA, 1991, p. 24). É, portanto, somente através da invocação do ontem que os mantinha unidos que os quatro amigos podem munir-se com as armas corretas para restaurar as lacunas do hoje e garantir a plenitude do amanhã.

\section{CONSIDERAÇÕES FINAIS}

A preocupação de Luandino com a experimentação de uma linguagem e uma estrutura narrativa não-lineares, trazida da modernidade, e com o resgate de um universo popular, trazida da tradição angolana, abrange em uma única tessitura narrativa o tradicional e o moderno. Ao fazê-lo, assinala-se a compreensão mais condizente nos dias de hoje de uma sociedade pós-colonial que se faz campo de batalha permanente entre fatores de manutenção e de mudança. A narrativa de Nós, os do Makulusu evoca a perspectiva utópica de Luandino de uma Angola alforriada do poder colonial, perspectiva esta que está em concordância com as ideias de Georges Balandier (1976) e Walter Benjamin (1985). Nela, completam-se a ênfase dada pelo sociólogo francês - sobre a compreensão da dialética que age entre os sistemas tradicional e moderno e que faz emergir um terceiro sistema caracterizado pela tensão constante dessa cultura e saber populares com as perturbações em cadeia trazidas pela modernidade - e aquela dada pelo filósofo alemão, sobre a possiblidade de se pensar o presente a partir da alternância do olhar moderno para o futuro e, sobretudo, para o passado.

Crê-se ainda que, como resultado de uma nação imersa em contradições sociais e ideológicas causadas pela luta pela independência, Nós, os do Makulusu vem impor a necessidade de uma discussão que extrapola questões sobre a modernidade, suas definições e suas consequências devastadoras em África. O romance mereceria ainda mais destaque no campo da literatura angolana contemporânea, pois as incongruências desse contexto social invadem sua tessitura, quebram com a ordem narrativa tradicional e balançam definições clássicas da figura do narrador e de espaço e tempo narrativos, suscitando, no terreno da teoria narrativa, o imperativo de se repensar essas e outras categorias em termos mais amplos e atualizados. 


\section{REFERÊNCIAS BIBLIOGRÁFICAS}

ADORNO, Theodor W. Notas de literatura I. Trad. Jorge de Almeida. São Paulo: Duas Cidades; Ed. 34, 2003.

BALANDIER, George. As dinâmicas sociais: sentido e poder. Trad. Gisela Stock; Hélio de Souza. São Paulo; Rio de Janeiro: DIFEL/ Difusão Editorial S. A. 1976.

BENJAMIN, Walter. O narrador: considerações sobre a obra de Nikolai Leskov. In: Magia e técnica, arte e política: ensaios sobre literatura e história da cultura. Trad. Sérgio Paulo Rouanet. São Paulo: Brasiliense, 1985, p. 197-221.

CHAVES, Rita. A formação do romance angolano. São Paulo: Universidade de São Paulo/Via Atlântica, 1999.

GAGNEBIN, Jeanne-Marie. Walter Benjamin: estética e experiência histórica. In: ALMEIDA, Jorge de; BADER, Wolfgang (orgs.). O pensamento alemão no século $X X$ : grandes protagonistas e recepção das obras no Brasil, vol. I. São Paulo: Cosac Naify, 2013, p. 175-200.

HABERMAS, Jürgen. O discurso filosófico da modernidade: doze lições. Trad. Luiz Sérgio Repa; Rodnei Nascimento. São Paulo: Martins Fontes, 2000.

MATA, Inocência. Literatura angolana. Silêncios e falas de uma voz inquieta. Luanda: Kilombelombe, 2001.

MARTIN, Vima Lia. O otimismo militante de Luuanda. Gragoatá: África, novos percursos. Niterói, n. 19, p. 79-93, 2005.

PAULA, Julio Cesar Machado de. O que ajunta espalha: tempo e paradoxo em Grande sertão: veredas, de João Guimarães Rosa, e Nós, os do Makulusu, de José Luandino Vieira. Tese de Doutoramento. Belo Horizonte: UFMG, 2010.

SANTIAGO, Silviano. Nas malhas da letra. Rio de Janeiro: Rocco, 2002.

VIEIRA, José Luandino. Nós, os do Makulusu. São Paulo: Ática, 1991.

Recebido para publicação em 06/05/2013

Aprovado em 19/08/2013 